\title{
GIÁ TRI TIÊN ĐOÁN CÁC THANG ĐIỂM CHILD-PUGH, FIB-4 VÀ SAAG TRONG DƯ ĐOÁN GIÃN TĨNH MACH THỰC QUẢN Ở BÊ̂NH NHÂN XƠ GAN CỔ CHƯớNG
}

\begin{abstract}
Võ Duy Thông ${ }^{1,2}$, Hồ Thị Vân $\mathrm{Anh}^{3}$, Hồ Tấn Phát ${ }^{2}$
TÓM TẮT.

Mục tiêu: Khảo sát khả năng dự đoán của các chỉ số khổng xâm lấn như SAAG, điểm Child-Pugh và FIB4 trong việc phát hiện giãn tĩnh mạch thực quản ở bệnh nhân xơ gan cổ chướng. Đối tượng và phương pháp: Nghiên cứu hồi cứu, cắt ngang mô tả tiến hành trên 75 bệnh nhân xơ gan cổ chướng nhập khoa Nội Tiêu hóa, bệnh viện Chợ Rẫy từ 10/2019 đển 06/2020. Tất cả bệnh nhân đều được đánh giá giãn tĩnh mạch thực quản bằng nội soi thực quản dạ dày tá tràng, xét nghiệm dịch màng bung và làm sinh hóa huyết học thường quy. Xác định điểm cắt, độ nhạy, độ đặc hiệu, diện tích dưới đường cong ROC của SAAG, FIB-4 và điểm Child-Pugh ở bệnh nhân xở gan cổ chướng có giãn lớn tĩnh mach thực quản. Kết quả: Trong số 75 bệnh nhân có $74,7 \%$ là nam, tuổi trung bình là 55,57 tuổi, $92 \%$ có giãn tĩnh mach thực quản.

Child-Pugh. Determination of cut-off point, sensitivity, specificity, area under the ROC curves of SAAG, FIB-4 and Child-Pugh score in patients with ascites with esophageal varices. Results: Among 75 patients, $74.7 \%$ were male, mean age was 55.57. and $92 \%$ patients had esophageal varices. SAAG and FIB-4 positively correlated with esophageal varices with $r=$ 0.499 and $0 / 327$, respectively. At cut-off point of 1.9 in patients with ascite cirrhosis, SAAG predicted esophageal varices with a sensitivity up to $88.37 \%$, a specificity of $75.87 \%$, and AUC of 0.982 . Predictive value of FIB-4 at 3.16 had sensitivity of $79.09 \%$, specificity of $68.75 \%$. The Child-Pugh scale had a low predictive value. Conclusion: Combined SAAG and FIB-4 were non-invasive parameters with high sensitivity for predicting esophageal varices in ascites cirrhosis patients.
\end{abstract} SAAG và FIB-4 có mối tương quan thuận với giãn tĩnh mạch thực quản với giá trị $r$ lần lượt là 0,499 và 0,327 . Tại điểm cắt 1,9 ở những bệnh nhân xơ gan cổ chướng ṠAAG tiên đoán giãn lớn tînh mach thức quản có độ nhạy lên đến $88,37 \%$, độ đặc hiệu $75,87 \%$, AUC là 0,902 . Giá trị tiên đoán của FIB-4 tại 3,16 có độ nhạy 79,09\%, độ đặc hiệu là 68,75\%. Thang điểm Child-Pugh có giá trị tiển đoán thấp. Kết luận: SAAG và FIB-4 là các chỉ số có giá trị tiên lượng tốt cho những bệnh nhân xơ gan cổ chướng có giãn lớn tĩnh mạch thực quản.

Tư khóa: xơ gan cổ trướng, giãn tĩnh mạch thực quản, SAAG, FIB-4

\section{SUMMARY}

\section{PROGNOSTIC VALUE OF CHILD-PUGH SCORE, FIB-4 AND SAAG TO PREDICT ESOPHAGEAL VARICES IN ASCITES CIRRHOSIS PATIENTS}

Objective: To investigate the predictability of noninvasive indicators such as SAAG, Child-Pugh score and FIB-4 in detecting varicose esophageal varices in patients with ascites cirrhosis Patients and methods: A retrospective cross-sectional study was conducted on 75 patients with ascites cirrhosis admitted to the Department of Gastroenterology, Cho Ray hospital from $10 / 2019$ to $06 / 2020$. All patients underwent gastroscopy, SAAG, FIB-4, classified into

${ }^{1}$ Đại học Y Dược Thành phố Hồ Chí Minh

${ }^{2}$ Bệnh viện Chợ Rẫy, Thành phố Hồ Chí Minh

${ }^{3}$ Bệnh viện $C$, Thành phố Đà Nã̃ng

Chịu trách nhiệm chính: Võ Duy Thông

Email: duythong@ump.edu.vn

Ngày nhận bài: 21.12.2020

Ngày phản biên khoa họ: 25.01.2021

Ngày duyệt bài: 2.2.2021
Key words; cirrhosis, esophageal varices, ascites, SAAG, FIB-4

\section{I. ĐĂT VẤN ĐỀ}

Xơ gan được định nghĩa là tình trạng tổn thương gan mạn tính do các tổn thương lặp đi lặp lại trong thời gian dài của nhiều căn nguyên. Đây cũng là một trong 10 nguyên nhân hàng đầu gây tử vong trên toàn thế giới - theo thống kê năm 2018[1]. Khi xơ gan tiến triển đến giai đoạn mất bù các biến chứng xảy ra nhiều hơn và nặng hơn, thường gặp nhất là giãn tĩnh mạch thực quản (có thể gầy xuất huyết), cổ trướng, hội chứng gan thận, nhiễm trùng dịch báng,... Tiên lượng bệnh nhân càng nặng nếu có càng nhiều biến chứng. Điều đáng chú ý là tỷ lệ tử vong khoảng 3,4\% mỗi năm ở những bệnh nhân có giãn tĩnh mạch thực quản nhưng chưa xuất huyết so với $57 \%$ mỗi năm đối với những bệnh nhân có giãn tĩnh mạch thực quản xuất huyết [2]. Do vậy xác định và theo dõi độ giãn tĩnh mạch thực quản là một vấn đề rất đáng được quan tâm đặc biệt là ở nhóm bệnh nhân xơ gan mất bù như xơ gan cổ trướng. Hiện nay, nội soi thực quản dạ dày tá tràng vần là phương pháp tốt nhất để xác định giãn tĩnh mạch thực quản ở bệnh nhân xớ gan, tuy nhiên vì sự xâm lấn, khó chịu và đòi hỏi kinh nghiệm nội soi của bác sĩ nên nhiêu bệnh nhân không thực hiện thủ thuật này, vậy nên các chỉ số không xâm lấn đã được nghiên cứu như SAAG, điểm Child-Pugh và FIB4. Tuy nhiên hiện tại chưa có nghiên cứu trong nước nào thực hiện để so sánh khả năng dự đoán của các phương pháp này nên chúng tôi đề 
nghị thực hiện đề tài này nhằm các mục tiêu sau:

(1) Khảo sát chỉ số $S A A G$, điểm Child-Pugh và FIB-4 ở bênh nhân xơ gan cổ chướng

(2) Xác đinh mối liên quan của $S A A G$, điểm Child-Pugh và $F I B-4$ với giãn lớn tĩnh mach thực quản

(3)Xác định khả năng dự đoán giãn tĩnh mạch thực quản của SAAG, điểm Child-Pugh và FIB-4

II. ĐỐI TƯỢNG VÀ PHƯƠNG PHÁP NGHIÊN CỨU

Thiết kế nghiên cứu: Nghiên cứu hồi cứu tiến hành trên hồ sơ bệnh án của 70 bệnh nhân xơ gan cổ trướng.

\section{Đôi tượng nghiên cứu:}

Tiêu chuẩn chơn bệnh nghiên cứu: Hồ sơ bệnh án của bệnh nhân được chẩn đoán xác định xớ gan cổ chướng điêu trị nội trú tại bệnh viện Chợ Rẫy từ 10/2019 đến 06/2020 đưa vào nghiển cứu triệu chứng lâm sàng, cận lâm sàng bao gồm nội soi thực quản da dày tá tràng, xét nghiệm dịch báng, sinh hóa và huyết học căn bản.

Tiêu chuấn loại trừ: Đã điều trị dự phòng giãn tĩnh mạch thực quản bằng ức chế beta không chọn lọc có hoặc không phối hợp với nhóm nitrate, đã thắt tĩnh mạch thực quản trên nội soi hoặc chích xơ, nhiễm trùng dịch báng hoặc ung thư gan.

Cỡ mẫu: Chọn mẫu thuận tiện (thỏa tiêu chuẩn chọn mẫu và không có tiêu chuẩn loại trừ)

Các bước tiến hành và phân tích số liệu: Từ hồ sơ bệnh án thu nhận các thông tin: chẩn đoán xác định xơ gan, đánh giá mức độ xơ gan bằng thang điểm Child-Pugh, đánh giá mức độ giãn tĩnh mạch thực quản theo phân độ của hội nghiên cứu tăng áp cửa Nhật Bản. Tính chỉ số SAAG và FIB-4 theo công thức:

SAAG = Albumin (huyết thanh) - Albumin (dịch màng bụng)

(Albumin huyết thanh và dịch màng bụng được lấy trong cùng 1 ngày trước khi sử dụng lợi tiểu và trước khi truyền albumin)

$$
\text { FIB-4 }=\frac{(\text { Tuổ } i) \times A S T(U / L)}{\left({ }^{\prime} i \text { ểu cầu }\left(10^{9} / L\right) \times \sqrt{A L T(U / L)}\right.}
$$

\begin{tabular}{|c|c|c|c|}
\hline 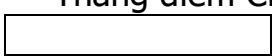 & 1 & 2 & 3 \\
\hline Bệnh não gan & Không & Độ 1-2 & Độ 3-4 \\
\hline Báng bụng & Không & Nhẹ & $\begin{array}{c}\text { Trung bình/ } \\
\text { nhiều }\end{array}$ \\
\hline $\begin{array}{l}\text { Bilirubin máu } \\
(\mathrm{mg} / \mathrm{dL})\end{array}$ & $<1$ & $2-3$ & $>3$ \\
\hline $\begin{array}{l}\text { Albumin huyết } \\
\text { thanh }(\mathrm{g} / \mathrm{dL})\end{array}$ & $>3,5$ & $2,8-3,5$ & $<2,8$ \\
\hline PT kéo dài (giấy) & $<4$ & $4-6$ & $>6$ \\
\hline Hoặc INR & $<1,7$ & $1,7-2,3$ & $>2,3$ \\
\hline Nếu xơ gan ứ & $<4$ & $4-10$ & $>10$ \\
\hline
\end{tabular}

Thang điểm Child-Pugh: mật: Bilirubin TP

$$
\text { ( } \mathrm{mg} / \mathrm{dL})
$$

Child-Pugh A: $<7$ điểm, Child-Pugh B: 7-9 điểm, Child-Pugh C: $\geq 10$ điểm

Phân tích số liêu theo phần mềm SPSS 20.0. Các mối liên hệ được kiểm định bằng phép kiểm X2 với $p<0,05$ được xem là có ý nghĩa thống kê.

Vấn đề đạo đức: Nghiên cứu đã được thông qua hội đồng đạo đức trong nghiên cứu $Y$ sinh học, Bệnh viện Chợ Rẫy.

\section{KẾT QUẢ NGHIÊN CứU}

Có 75 hồ sơ bệnh án của bênh nhân đủ tiêu chuẩn được đưa vào nghiên cứu với tuổi trung bình là $55,57 \pm 12,87$ (nhỏ nhất là 19 và lớn nhất là 79). Phân bố về tuổi, giới, mức độ xơ gan - điểm Child-Pugh, đặc điểm nội soi thực quản da dày tá tràng, chỉ số $S A A G$, tỷ số AST/ALT và chỉ số FIB-4 của các bệnh nhân được trình bày ở các bảng 1-4. Có 25,3\% (19/75) bệnh nhân nữ và $74,7 \%$ (56/75) bệnh nhân nam. Tỷ lệ Nam/Nữ là 2,9/1. Chủ yếu bệnh nhân thuộc nhóm Child C (76\%), Giãn tĩnh mạch thực quản độ II chiếm tỷ lệ cao nhất trong nhóm nghiên cứu $(41,3 \%)$. SAAG của mẫu nghiên cứu phân bố trong khoảng $1,2-3,4 \mathrm{mg} / \mathrm{dl}$ trung bình là $1,9 \pm 0,42 \mathrm{mg} / \mathrm{dl}$, FIB-4 phân bố từ 0,51 đến 10,24 và trung bình là $2,96 \pm 1,94$. Giá trị trung bình của điểm Child-Pugh, SAAG, FIB-4 ở nhóm có giãn tĩnh mạch thực quản đều cao hơn nhóm không giãn tĩnh mạch thực quản trên nội soi.

Bảng 1. Đặc điểm về tuổi và giới tính của bệnh nhân

\begin{tabular}{|c|c|c|c|}
\hline Nhóm tuối & Nam & Nữ & $\mathbf{n ~ ( \% ) ~}$ \\
\hline$<30$ tuối & 3 & 0 & $3(4,0 \%)$ \\
\hline $30-39$ tuối & 3 & 0 & $3(4,0 \%)$ \\
\hline $40-49$ tuối & 13 & 3 & $16(21,3 \%)$ \\
\hline $50-59$ tuối & 21 & 1 & $22(29,3 \%)$ \\
\hline $60-69$ tuối & 12 & 11 & $23(30,7 \%)$ \\
\hline$\geq 70$ tuối & 4 & 4 & $8(10,7 \%)$ \\
\hline Tống cộng & $\mathbf{5 6}$ & $\mathbf{1 9}$ & $\mathbf{7 5 ( 1 0 0 \% )}$ \\
\hline
\end{tabular}

Bảng 2: Mức độ Xơ gan theo Child-Pugh

\begin{tabular}{|c|c|c|}
\hline Mức độ & Tân suất & Tỷ lệ \% \\
\hline Child $A$ & 1 & 1,3 \\
\hline Child $B$ & 17 & 22,7 \\
\hline Child C & 57 & 76,0 \\
\hline Tống cộng & $\mathbf{7 5}$ & $\mathbf{1 0 0}$ \\
\hline
\end{tabular}

Bảng 3. Đặc điếm của tĩnh mạch thực quản trên nôi soi

\begin{tabular}{|c|c|c|}
\hline Nội soi TMTQ & Tân suất & Tỷ lệ \% \\
\hline Không giãn & 6 & 8,0 \\
\hline Độ I & 22 & 29,3 \\
\hline Độ II & 31 & 41,3 \\
\hline Độ III & 16 & 21,4 \\
\hline Tống cộng & $\mathbf{7 5}$ & $\mathbf{1 0 0}$ \\
\hline
\end{tabular}


Bảng 4. Khảo sát điểm Child-Pugh, chỉ số SAAG, tỷ số AST/ALT và FIB-4

\begin{tabular}{|c|c|c|c|c|c|}
\hline Chỉ số & Lớn nhất & Nhỏ nhất & Trung bình & Giãn TMTQ & Không giãn \\
\hline Điếm Child-Pugh & 13 & 6 & $10,53 \pm 1,46$ & $10,64 \pm 1,45$ & $9,03 \pm 0,82$ \\
\hline SAAG & 3,4 & 1,2 & $1,90 \pm 0,42$ & $1,95 \pm 0,39$ & $1,35 \pm 0,19$ \\
\hline AST/ALT & 1,66 & 0,13 & $0,67 \pm 0,33$ & $0,69 \pm 0,33$ & $0,49 \pm 0,17$ \\
\hline FIB-4 & 10,24 & 0,51 & $2,96 \pm 1,94$ & $3,08 \pm 1,96$ & $1,67 \pm 1,28$ \\
\hline
\end{tabular}

Khi phân tích các yếu tố dự đoán giân tĩnh mạch thực quản thì điếm Child Pugh, SAAG và FIB-4 đều là yếu tố đáng tin cậy với $p<0,05$, trong khi đó tỷ số AST/ALT có $p>0,05$ nên đây không phải là một yếu tố dự đoán có ý nghĩa thống kê (Bảng 5).

Bảng 5. Các yếu tố dự đoán giân tînh mạch thực quản

\begin{tabular}{|c|c|c|c|}
\hline Yếu tố dứ đoán & OR & Độ tin cậy 95\% & P \\
\hline Điếm Child-Pugh & 3,6059 & $0,658-19,6964$ & 0,014 \\
\hline SAAG & 19,6429 & $2,1211-18,9096$ & 0,0087 \\
\hline AST/ALT & 3,2143 & $0,3559-9,0332$ & 0,2984 \\
\hline FIB-4 & 7,200 & $1,2007-24,1784$ & 0,0308 \\
\hline
\end{tabular}

SAAG, FIB-4 và điểm Child-Pugh đều cho thấy có mối tương quan thuận với giãn tĩnh mạch thực quản (Bảng 6).

Bảng 6. Mối liên quan của SAAG, điểm Child-Pugh và FIB-4 với giãn tĩnh mạch thực quản

\begin{tabular}{|c|c|c|c|}
\hline Yếu tố dự đoán & $\mathbf{r}$ & Độ tin cậy 95\% & $\mathbf{P}$ \\
\hline Điếm Child-Pugh & 0,363 & $0,0383-0,462$ & 0,0226 \\
\hline SAAG & 0,499 & $0,189-0,574$ & 0,0004 \\
\hline FIB-4 & 0,327 & $0,0059-0,432$ & 0,0501 \\
\hline
\end{tabular}

Điếm cắt đế dự đoán giãn tĩnh mạch thực quản của SAAG và FIB-4 lần lượt là 1,7 và 2,45 . Đế dự đoán giãn lớn tĩnh mạch thực quản điểm cắt của SAAG là 1,9 và FIB-4 là 3,16 . Diện tích dưới đường cong AUC khi dự đoán bằng SAAG lớn hơn của FIB-4 (Bảng 7).

Bảng 7. Giá trị điểm cắt của FIB-4 với giãn tînh mạch thực quản

\begin{tabular}{|c|c|c|c|c|c|c|c|}
\hline & TMTQ & Cut off & $\begin{array}{c}\text { Đố nhạy } \\
(\%)\end{array}$ & $\begin{array}{c}\text { Đố đăc } \\
\text { hiệu (\%) }\end{array}$ & $\begin{array}{c}\text { GTTD } \\
(+)\end{array}$ & $\begin{array}{c}\text { GTTD } \\
(-)\end{array}$ & AUC \\
\hline \multirow{2}{*}{$\begin{array}{c}\text { Điếm Child- } \\
\text { Pugh }\end{array}$} & Giãn TMTQ & 9 & 53,62 & 87,37 & $94,74 \%$ & $16,67 \%$ & 0,774 \\
\hline & Giãn lớn & 10 & 51,16 & 78,12 & $57,97 \%$ & $50,07 \%$ & 0,509 \\
\hline \multirow{2}{*}{ FIB-4 } & Giãn TMTQ & 2,45 & 78,26 & 66,67 & $96,43 \%$ & $21,05 \%$ & 0,742 \\
\hline & Giãn lớn & 3,16 & 79,07 & 68,75 & $76,74 \%$ & $68,75 \%$ & 0,738 \\
\hline \multirow{2}{*}{ SAAG } & Giãn TMTQ & 1,7 & 73,91 & 88,43 & $98,21 \%$ & $26,32 \%$ & 0,923 \\
\hline & Giãn lớn & 1,9 & 88,37 & 75,87 & $74,42 \%$ & $71,87 \%$ & 0,902 \\
\hline
\end{tabular}

\section{BÀN LUÂ̂N}

Có 75 bệnh nhân được đưa vào nghiên cứu với 56 bệnh nhân là nam $(74,7 \%)$ và 19 bệnh nhân là nữ $(25,3 \%)$, tuổi từ 19 đến 79 tuổi, trung bình là 55,57 $\pm 12,87$, nhóm tuổi từ 50-69 tuổi chiếm tỷ lệ nhiều nhất (60\% mấu nghiên cứu). Các kết quả này nằm trong đặc điểm nhân trắc của bệnh xơ gan trên thế giới, cũng như phù hợp với dịch tễ xơ gan tại Việt Nam như độ tuổi phát hiện bệnh thường là trung niên và tỷ lệ nam mắc nhiều hơon nữ.

Bệnh nhân xơ gan có cổ chướng là tiêu chuẩn chọn bệnh chính mà đây là một trong các biểu hiện nặng - mất bù của xơ gan nên phân loại xơ gan theo Child-Pugh nhiêu nhất là Child $C$ là phù hợp (76\% bệnh nhân), điều này cũng phù hợp với nơi làm nghiên cứu là bệnh viện Chợ Rẫy nơi điều trị bệnh nhân nặng của vùng Đông Nam Bộ. Đi kèm với cổ chướng thì các biến chứng nguy hiểm khác như giãn tĩnh mạch thực quản cũng gia tăng đáng kể trên nhóm bệnh nhân này. Cụ thể có đến $92 \%$ bệnh nhân xớ gan cổ chướng có giãn tĩnh mạch thực quản trong đó $62,7 \%$ bệnh nhân giãn lớn tĩnh mạch thực quản (độ II và độ III). Tỷ lệ giãn tĩnh mạch thực quản trong nghiên cứu trong nghiên cứu của Vũ Bích Thảo, Hà Vũ, Sayyed cũng khá cao từ $78 \%$ đến $86,9 \%$, khá tương đồng với nghiên cứu của chúng tôi [2],[3],[4].

Nghiên cứu của chúng tôi đánh giá SAAG, FIB-4 và điểm Child-Pugh cho kết quả có mối tương quan thuận với giãn tĩnh mạch thực quản. Các chỉ số dự đoán tính toán được từ nghiên cứu cho thấy SAAGG, FIB-4 đều là những chỉ số không xâm lấn có giá trị cao trong dự đoán giãn tĩnh mạch thực quản. Phân bố của SAAG trong nghiên cứu từ 1,2 đến $3,4 \mathrm{mg} / \mathrm{dl}$, trung bình là $1,90 \pm 0,42 \mathrm{mg} / \mathrm{dl}$, nhóm có giãn tĩnh mạch cao hơn nhóm không giãn. FIB-4 phân bố từ 0,51 đến 10,24 , trung bình là $2,96 \pm 1,94$. FIB-4 tại 
giá trị 3,16 cho giá trị dự đoán giãn lớn tĩnh mạch thực quản với độ nhạy 79,07\%, độ đặc hiệu $68,75 \%$ và diện tích dưới đường cong là 0,738 . Nghiên cứu của Kraja $B$ cho rằng tại FIB-4 $=3,23$ có khả năng dự đoán giãn tĩnh mạch thực quản với độ nhạy $72 \%$, độ đặc hiệu $58 \%$, và AUC 0,66 [5]. Trong nghiên cứu của Hà Vũ trên bênh nhân xơ gan nói chung thì điểm cắt dự đoán giãn tĩnh mach thực quản cao hơn - tại cut-off 7,065 cho độ nhạy 98,5\%, độ đặc hiệu $71,1 \%$ [2]. Đối với SAAG, trong nghiên cứu của chúng tôi nhận thấy rằng khả năng dự đoán tối ưu hơn với tại giá trị điểm cắt là 1,9 có độ nhạ $88,37 \%$, độ đặc hiệu $75,87 \%$ và AUC đến 0,902 . Đối với điểm Child-Pugh-đây là một thang điểm (bao gồm cả lâm sàng và cânn lâm sàng) đánh giá độ nặng của bệnh gan tuy nhiên giá trị tương quan và dự đoán giãn tĩnh mạch theo thống kê tính được không cao bằng SAAG và FIB-4. Nghiên cứu của Sayyed về SAAG và APRI ở bênh nhân có bệnh gan mạn đã cho thấy rằng SAAG càng lớn phối hợp với APRI càng thấp là một chỉ số không xâm lấn hữu ích trong dự đoán giãn tĩnh mach thực quản với độ nhạ lển đên $94 \%$ (tính riêng đồ nhay của SAAG là $77,6 \%$ và APRI là $74,1 \%$ ) từ đó có lợi cho xác định sớm bệnh nhân cần chuyển cho phòng nội soi [4]. Từ các nghiên cứu và các nhận định trên rút ra rằng việc sử dụng 2 thông số SAAG và FIB-4 hoặc sử dụng kết hợp cả hai có thể làm tăng độ tin cậy trong việc dự đoán giãn tĩnh mach thực quản ở những bệnh nhân xơ gan đặc biệt đối với nhóm có nguy cơ cao như xơ gan cổ chướng. Điều này có thể vừa giúp làm giảm chi phí và sự khó chịu cho những bệnh nhân xơ gan cổ chướng vừa làm giảm gánh nặng cho các đơn vị nội soi.

\section{KẾT LUÂN}

Trong các thang điểm, điểm Child-Pugh đánh giá độ nặng của gan, tuy nhiên giá trị tương quan và dự đoán giãn tĩnh mạch thực quản không cao. SAAG và FIB-4 là 2 thông số không xâm lấn với độ nhạy cao (lần lượt là $88,37 \%$ và $79,07 \%$ ) để dự đoán giãn tĩnh mạch thực quản ở bệnh nhân xớ gan cổ chướng và do đó có ích trong việc xác định bênh nhân cần chuyển đến những cơ sở điều trị có thể can thiệp nội soi.

\section{TÀI LIÊU THAM KHẢO}

1. Murphy S.L, Xu J, Kochanek K.D, et al. Mortality in the United States, 2017. NCHS Data Brief 2018, 328:1-8. 5

2. Hà Vũ, Bùi Hữu Hoàng. Giá trị của chỉ số $A P R I$ và FIB-4 trong tiên đoán giãn tĩnh mach thực quản ở bênh nhân xơ gan. Tap chí Y Hoc Thành phố Hồ Chí Minh 2015; 19(1):97-102. 3

3. Vũ Bích Thảo, Trân Ngoc Ánh. Giá trị chẩn đoán của độ chênh Albumin huyết thanh và dịch màng bụng trong chẩn đoán phân biệt cổ trướng do xơ gan với các nguyên nhân khác. Tap chi Nghiên cứu Y học 2013; 82(2): 44-48.

4. Sayyed J, Sharma D, Choudhary $K$, et al. A Study on Correlation between SAAG and Platelet Count: Spleen Size Ratio for the Prediction of Esophageal Varices among Chronic Liver Disease Patients. Indian Journal of Basic and Applied Medical Research 2015, 7 (3): 502 - 508.

5. Kraja B, Mone I, Akshija I, et al. Predictors of esophageal varices and first variceal bleeding in liver cirrhosis patients. World J Gastroenterol 2017, 23 (26): 4806-4814.

\title{
ĐÁNH GIÁ THỰC TRẠNG BỆNH LÝ TRÀO NGƯỢC DẠ DÀY THỰC QUẢN KHÁNG TRI VÀ NHU CẦU SỬ DỤNG ỨNG DUNG DI ĐộNG NHẰM HỖ TRỢ QUẢN LÝ BÊ̂NH
}

\author{
Đào Việt Hằng1,2, Trần Thị Ngọc Ánh², Nguyễn Mạnh $\mathrm{Duy}^{2}$
}

\section{TÓM TẮT}

Khảo sát được tiến hành từ tháng 4 đến tháng 8 năm 2020 nhằm đánh giá thực trạng bệnh lý trào ngược dạ dày- thực quản (GERD) kháng trị trong thực hành lâm sàng và nhu câu sử dụng ứng dụng di động

\footnotetext{
${ }^{1}$ Trường Đai họ Y Hà Nọi

2Viên Nghiên cứu và Đào tao Tiêu hóa, Gan mật Chịu trách nhiệm chính: Đào Việt Hằng

Email: daoviethang@hmu.edu.vn

Ngày nhân bài: 22.12.2020

Ngày phản biên khoa hoc: 22.01.2021

Ngày duyệt bài: 1.2 .2021
}

(ƯDDĐ) hỗ trợ quản lý bệnh. Có 101 bác sỹ đã tham gia nghiên cứu, trong đó $97 \%$ bác sỹ đã từng điều tri cho bệnh nhân trào ngược da dày- thực quản, $88 \%$ bác sỹ đã từng găp bênh nhẩn không đáp ứng điều trị. $71,7 \%$ các bác sỹ ghi nhận tỷ lệ bệnh nhân không đáp ứng điêuu trị trong thực tế $\geq 10 \%$. Phối hợp thêm thuốc, tăng liều hay thay đổi thuốc PPI là những xử trí phổ biến của các bác sỹ khi điều trị cho bệnh nhân GERD kháng trị. $100 \%$ bác sỹ đồng ý với việc xây dưng môt ƯDDĐ quản lý bênh trào ngược da dày-thực quản cho bệnh nhân. Tính năng các bác sỹ mong muốn xây dựng trong ƯDDĐ bao gồm hướng dấn về chế độ ăn uống, sinh hoạt, cung cấp kiến thức về bênh và là kênh tương tác giữa bác sỹ và bênh nhân. 